Noticias

Política de C\&T

\section{Em revisão: 0 impacto da produção científica brasileira para o Brasil}

Nos anos 1960, Eugene Garfield desenvolveu indicadores para organizar e avaliar referências bibliográficas da área de medicina, com o objetivo de minimizar a subjetividade humana na seleção e indexação de obras e aumentar a eficiência da busca por informações relacionadas a um tema de pesquisa. Garfield fundou o Institute of Scientific Information (ISI) e influentes bases de dados internacionais, como o Web of Science (WoS) que reúne uma seleta gama de revistas científicas e divulga indicadores como o fator de impacto (FI) - média de citaçôes que os artigos de uma revista recebe nos dois anos anteriores. Mais do que meras ferramentas, os indicadores acabaram se tornando metas para as políticas científicas.

Apesar de a ciência brasileira estar crescendo acima da média mundial nos últimos anos - sobretudo a partir dos anos 1990, a participação do país na produção científica internacional passou dos apenas $1 \%$ para $2,5 \%$, em 2013 - permanece a queixa de que o número de citações dos artigos brasileiros no exterior se manteve estável. Assim, a meta dos últimos anos não é aumentar a quantidade de artigos, mas sua qualidade, traduzida

Artigos publicados e seu impacto - Brasil, 1981-2013
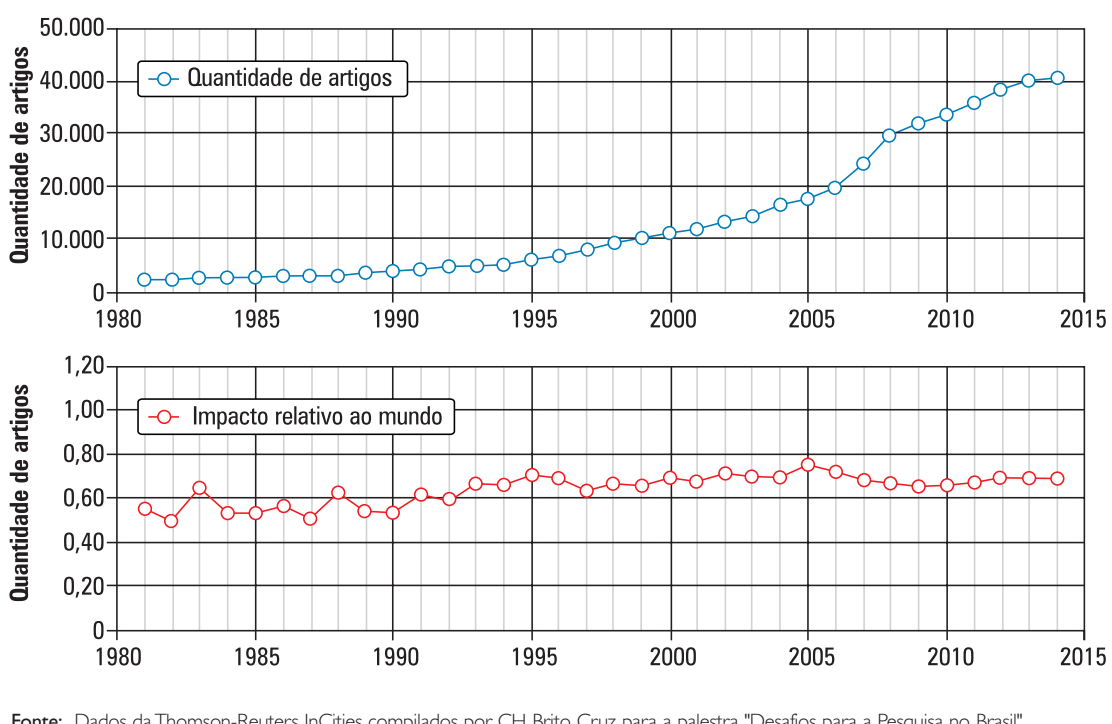

Fonte: Dados da Thomson-Reuters InCities compilados por CH Brito Cruz para a palestra "Desafios para a Pesquisa no Brasil"

pelo número de citaçóes de artigos de autores brasileiros indexados nos consagrados Scopus, da editora holandesa Elsevier, e WoS.

Para Lea Velho, especialista em estudos sociais da ciência do Instituto de Geociências da Universidade Estadual de Campinas (Unicamp), os fatores que levam uma pessoa a citar um artigo não têm relação com a sua qualidade. "É como se estivéssemos induzindo as pessoas a acharem que aqueles números [citaçôes] refletem qualidade. A citação é um ato social, não de mérito", afirma Lea, que nos anos 1980 publicou artigos sobre a prática de citação. Ao mesmo tempo ela lembra uma das regras básicas da cienciometria na qual as comparações só valem se compararem iguais com iguais, ou seja, as mesmas áreas do conhecimento e não a soma de todas elas em nações diferentes. "Não há nenhum problema de usarmos esses indicadores como suporte a processos de avaliação. O que não concordamos é com o uso indiscriminado", conclui Jacqueline Leta, professora adjunta do Instituto de Bioquímica Médica da Universidade Federal do Rio de Janeiro (UFRJ) e que se dedica aos estudos de cienciometria.

INDUZINDO MUDANÇAS Outra regra da cienciometria é que os indicadores de produção científica acabam modelando comportamentos, como o aumento no número de publicações, independentemente da qualidade $\mathrm{e}$ o direcionamento da pesquisa para temas de maior visibilidade internacional, por exemplo, o que contribui 


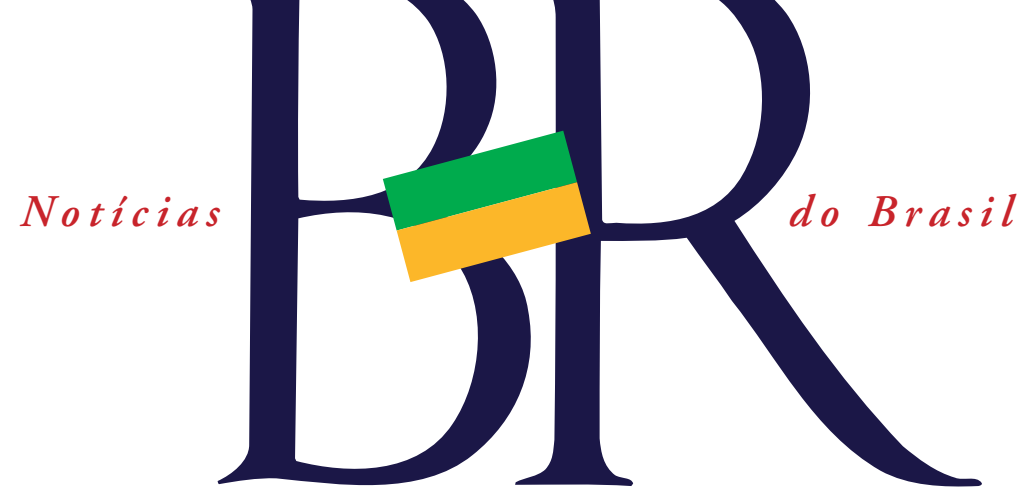

Evolução do impacto relativo. países selecionados

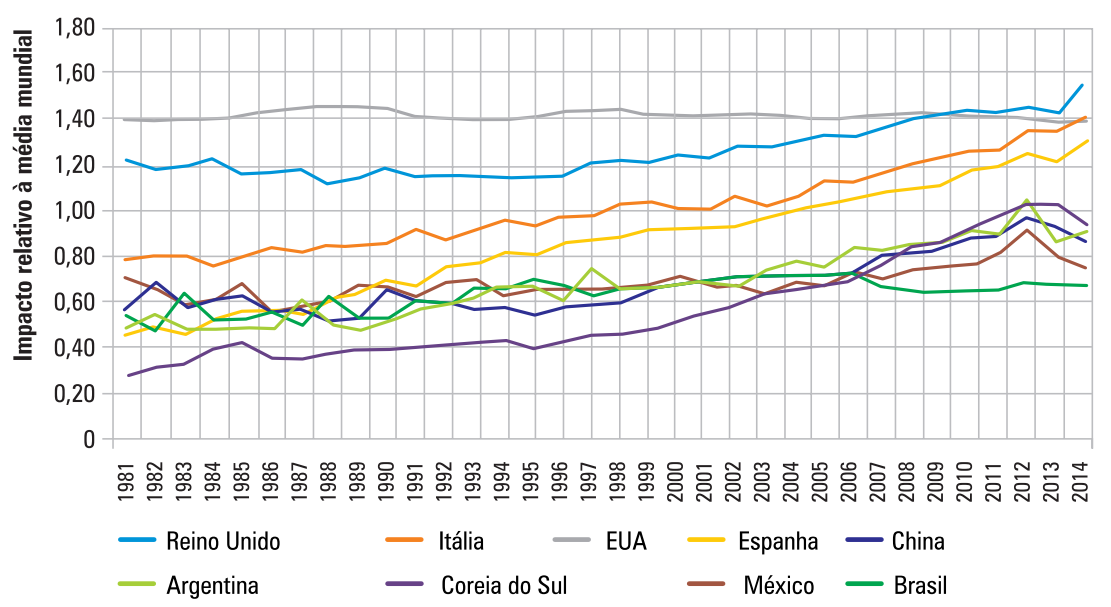

Fonte: Dados da Thomson-Reuters InCities compilados por CH Brito Cruz para a palestra "Desafios para a Pesquisa no Brasil"

para efeitos deletérios ao sistema. Talvez essa tenha sido uma das razões pela qual a Austrália extinguiu, em 2011, seu sistema de classificações de revistas científicas. A classificação era controversa para inúmeras áreas, por exemplo, as multidisciplinares, as novas e aquelas com ênfase mais regional, que acabavam prejudicadas com o ranking. $\mathrm{O}$ país preferiu deixar que cada área determinasse suas prioridades de publicação.

As classificações também influenciam a percepção de que os bons artigos estão apenas nas revistas melhor colocadas. "Não temos necessariamente que publicar em revistas de mainstream e ser citados no exterior! Esse não é o objetivo da política. Precisamos é produzir conhecimento para saber resolver os problemas que temos", defende Lea Velho.
NACIONALMENTE RELEVANTE Quando a ênfase são os indicadores internacionais, como fica a produção científica brasileira que não pode ser contabilizada a partir dessas bases de dados, como, por exemplo, a de áreas do conhecimento que tradicionalmente publicam em português? Leta estima que existam cerca de mil revistas científicas no Brasil. Destas, cerca de 400 estão indexadas em bases como a brasileira SciELO (Scientific Eletronic Library Online), mas ainda há inúmeras outras publicações indexadas, por exemplo, nos 162 portais de periódicos científicos listados pelo Instituto Brasileiro de Informação em Ciência e Tecnologia (Ibict) que usam o Sistema Eletrônico de Editoração de Revistas (SEER) e outras tantas ainda não indexadas. "Quem não está indexado não tem indica- dor”, resume Rogério Mugnaini, cientista da informação da Universidade de São Paulo (USP), que tem se dedicado a estudar indicadores para a produção nacional. Ele propõe o desenvolvimento de indicadores que levem em consideração as especificidades de cada área do conhecimento e que considerem também as publicações que não estão indexadas no SciELO ou nos principais indexadores estrangeiros. $\mathrm{O}$ principal é "ver o que é importante para os brasileiros". Segundo ele, a combinação de indicadores de impacto nacionais e internacionais valoriza a produção local.

$\mathrm{O}$ atual sistema de avaliaçôes de cursos de pós-graduação, desenvolvido pela Coordenação de Aperfeiçoamento de Pessoal de Nível Superior (Capes), classifica, desde 2001, as revistas científicas brasileiras, constituindo-se como um dos indicadores de qualidade. A classificação Qualis Periódicos acaba definindo as escolhas na hora de publicar um artigo, bem como cria a percepção de que ela reflete a qualidade, não apenas das revistas, mas dos próprios artigos. Há inúmeras inconsistências, no entanto, que colocam o sistema no epicentro da polêmica na academia. Dentre elas o fato de colocar nos principais estratos, A1 e A2, lado a lado, revistas brasileiras, com menor rigor de avaliação, e publicações internacionais, com critérios claros e rigorosa avaliação por pares, não incluir revistas importantes para a área do conheci- 
